\title{
Psychiatric Diagnosis, Type of Crime and Victim Profile: A Study of the Population of a High-Security Forensic Hospital in the State of Sao Paulo, Brazil
}

\author{
Eduardo H. Teixeira ${ }^{1}$, Paulo Dalgalarrondo ${ }^{2}$, \\ ${ }^{1}$ Psychiatrist, Clinical Professor of Psychiatry and Forensic Psychiatry, Medical School of the \\ Catholic University of Campinas (PUC), São Paulo, Brazil. \\ ${ }^{2}$ Psychiatrist, Clinical Professor of Psychiatry, Medical School of the State University of Campinas \\ (UNICAMP), São Paulo, Brazil. \\ eduardo.psiquiatra@icloud.com
}

\begin{abstract}
To study the population of a high-security forensic hospital, utilizing its criminal records, clinical diagnoses and victim profiles. The records of 269 patients male were analyzed. Psychotic disorders were the most common findings (58\%). The most common type of crime was murder or attempted murder (52.8\%), and there was a significant correlation between psychotic disorders and this type of crime $(p<0,05) .89 .7 \%$ of these crimes led to death, and $34.5 \%$ of the time the victim was a close relative. Mentally retarded patients committed proportionally more sex crimes, when compared to psychotic patients and considering only sex crimes and attempted murder $(p<0,05) .78 .5 \%$ of sex crimes involved victims that were under 14 years old. The data on the victims, including murders committed by psychotic patients and sex crimes committed by mentally retarded individuals, show that aspects of the victim's profile are to be considered when analyzing the crime.
\end{abstract}

Keywords: Forensic psychiatry, mental disease, violent behavior, victim profile, high-security hospital, House of Custody and Psychiatric Treatment, Brazil.

\section{INTRODUCTION}

The relationship between crime and mental disorder is complex and has long been the subject of intense study 1-4. There is, furthermore, still considerable controversy on the matter of whether and in what way these two aspects of human experience, present in every human society, would be interrelated ${ }^{5,6}$.

Study that evaluated all homicides committed by persons in contact with mental health services in England between 1994 and 2002 identified the most perpetrators of homicide were male, with a diagnosis of schizophrenia or other psychotic illness. Victims are most likely to be a family member or an acquaintance. Psychotic symptoms as well as alcohol or substance misuse were found to be present at the time of homicide7.

In most legislation in many and diverse countries, the individual that has committed a criminal act as a result of a psychiatric disorder, the causal connection between the two having been demonstrated, is not liable for criminal punishment, but must be sequestered and treated in a special institution8-10.

In Brazil, mental patients who have committed offenses and crimes and were considered not guilty by reason of insanity are not sent to high-security wards in mental hospitals or to psychiatric wings of prisons. They are sent to forensic hospitals, designated "House of Custody and Psychiatric Treatment", previously called "Judicial Asylum". The House of Custody and Psychiatric Treatment have, officially, a dual objective: to isolate the individual for the protection of society, and to treat people with serious mental disorders so that they may, at least theoretically, be eventually released ${ }^{11-}$ 13. The first "Judicial Asylum" in Brazil was created in 1921 in Rio de Janeiro, with the second emerging in 1925 in the state of Rio Grande do Sul ${ }^{12}$.

Few studies have adequately evaluated the profile of the inmate populations of these institutions. Menezes, in 1996, evaluated the population of the House of Custody and Psychiatric Treatment "Dr. Maurício Cardoso", in state of Rio Grande do Sul, Brazil. Its inmates are characterized by a 
preponderance of males (91\%), people between 30 and 49 years of age $(69 \%)$, unmarried $(79 \%)$ and illiterate or with incomplete elementary education (84\%). This study revealed, with regards to crime, that: $74 \%$ of inmates had committed violent crimes (homicide, attempted murder or assault) and 9\% had committed sexual crimes. As for the diagnoses, there was a predominance of schizophrenia (62\%), followed by $8 \%$ with mental retardation, $7 \%$ with personality disorders and $6 \%$ with bipolar disorder ${ }^{12}$.

There are several detailed studies that have been conducted with wide-ranging investigations. In England, the inmate populations of three "special" psychiatric hospitals were studied. These hospitals were high-security and treated patients that had been tried and posed a risk of violence. The records of 1740 patients were analyzed between January and June $1993^{14}$. These populations were characterized by a preponderance of male patients $(83 \%)$, of patients between 20 and 50 years old (82\%), with an average age of 39.4 years. The diagnoses consisted mostly of schizophrenia and delusional disorder (53\%), followed by $16 \%$ with mental retardation. Personality disorders showed up in $41 \%$ of all cases, as main diagnosis or comorbidity. The most frequent crimes were split up into four distinct groups: homicide, other violent crime, sexual crime or offense, and property damage ${ }^{14}$.

Another similar study, performed in a medium-security forensic-psychiatric service, examined 2608 patients admitted into institutions in seven different regions of England. The average age of the patients was 31.6, with a predominance of male and unmarried patients. Regarding the diagnosis, a majority of psychotic patients was observed, and among the crimes committed, the majority was crimes against life; however, these numbers displayed some variations, attributed to the regional differences between the services. The same was the case in terms of diagnoses of personality disorders and use of psychoactive substances ${ }^{15}$.

In a study conducted by Tuninger et al (2001) in Sweden, 257 patients admitted to an emergency psychiatric unit for individuals that posed a risk of violence were evaluated for a period of 14 months. The average age observed was 41.3 , with a predominance of male patients $(n=160 ; 62.2 \%)$ and of psychotic patients $(n=228 ; 88.6 \%)$. In terms of type of crime, broken up into violent and nonviolent crimes, psychotic patients were those who most committed violent crimes. The study also identified $40 \%$ comorbidity with the use of drugs, and $38 \%$ of patients had a criminal record, a rate much higher than that of the general population ${ }^{16}$.

In São Paulo state, the first "Judicial Asylum" was opened in 1927, now called the House of Custody and Psychiatric Treatment "Prof. André Teixeira Lima", located in Franco da Rocha municipality.

This institution faces longstanding issues, its poor conditions with respect to housing, medical services and rehabilitation being widely acknowledged. However, it has recently been undergoing some changes. Currently, for instance, the House boasts a transitional forensic service (partial commitment), allowing for a process of progressive de-institutionalization ${ }^{17}$. The population of this institution is made up of individuals of both sexes and of heterogeneous socio-demographic, clinical and criminal profiles.

Given the challenges of the development of scientific knowledge that will support therapeutic and rehabilitation practices that are minimally effective ${ }^{18}$, an analysis of this particular patient population becomes necessary, comparing it to other institutions with a similar profile. Furthermore, this study is intended to help identify demographic and clinical elements that might allow for a better exploration of violent behavior in people with severe mental disorders.

\section{Methodology}

The charts of 269 patients of the House of Custody and Psychiatric Treatment "Franco da Rocha" for the period between March and July 2005 were examined.

The data were collected from the psychiatric-criminal charts, which make up only part of the full patient chart; all information relevant to this study could be found in the partial charts. The data registered included socio-demographic, criminal and clinical-diagnostic aspects of the psychiatric charts, which had been filled out by experts at the institution.

Only the male population was considered in this study, given that it is the predominant population of the institution and because the data presented here will serve as a basis for a later study about delusion and crime in male psychotic patients committed to this institution.

All data were organized in spreadsheets, displayed in graphs and tables and analyzed with the statistical program SPSS, version 7.5. 


\section{RESUlTS}

The total inmate population at the institution at the beginning of the study was 498, made up of 91 (18\%) females and $407(82 \%)$ males. Of these 407 (82\%), 12 (3\%) were defendants transferred from jail for temporary treatment, $126(31 \%)$ had been committed few months previous and still did not have diagnostic reports attached to their charts, and 269 (66\%) comprised those patients that were analyzed and which were relevant to this study.

In table 1 , the examined cases were distributed by age range. The minimum age of patients studied was 23 , the maximum was 75 , and the average was $40.7(\mathrm{SD}= \pm 9.7)$. A predominance of subjects between 30 and 49 years of age was observed, corresponding to $164(61.6 \%)$ patients.

Table1. Distribution of the sample analyzed for age $(n=269)$

\begin{tabular}{|l|c|c|}
\hline \multicolumn{1}{|c|}{ Age Distribution } & N & \% \\
\hline 20-29 Years & 35 & 13,0 \\
\hline 30-39 Years & 97 & 36,1 \\
\hline 40-49 Years & 69 & 25,5 \\
\hline 50-59 Years & 31 & 11,5 \\
\hline 60-69 ears & 12 & 4,50 \\
\hline >70 Years & 1 & 0,40 \\
\hline Unknown & 24 & 9,00 \\
\hline Total & 269 & 100,0 \\
\hline
\end{tabular}

According to the charts, though there are many cases lacking annotations, and the information collected from professionals that have worked at the institution for many years, the population seems to be comprised of mostly unmarried people with a low level of education, though these data could not be analyzed statistically because of the high amount of missing data.

Graphic 1 displays the distribution of studied patients, according to the main clinical diagnosis of the latest annexed institutional report, considering the diagnostic criteria adopted by the CID $10{ }^{19}$. In 8 (3\%) of the cases, information about the clinical diagnosis was still lacking. A predominance of psychotic disorders was observed, $\mathrm{n}=156(58 \%)$, which include schizophrenias, delusional disorders, acute psychotic episode and schizoaffective disorders.

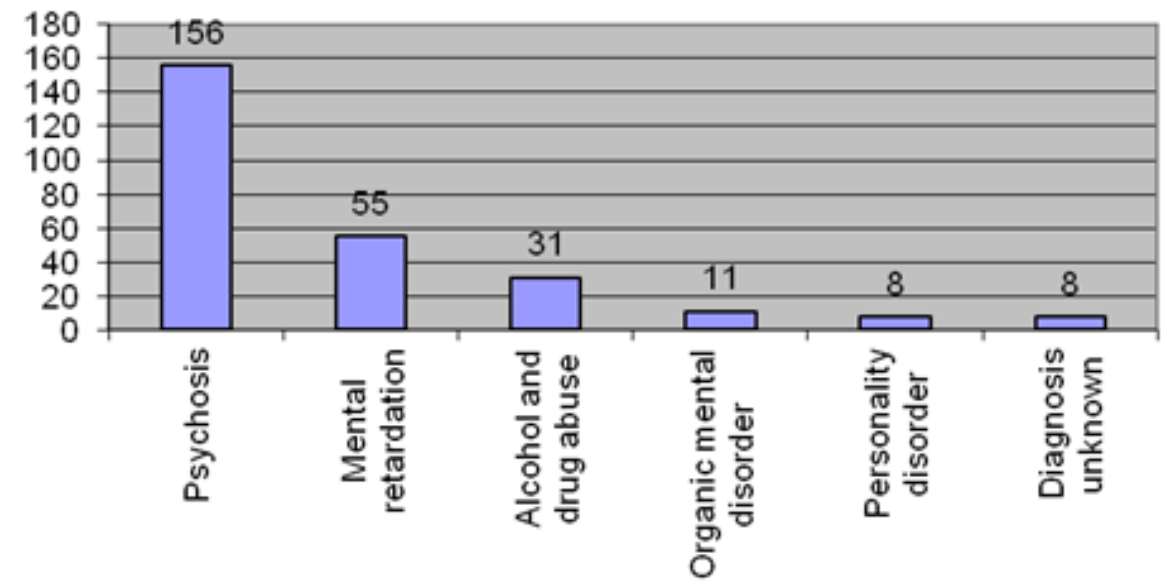

Graphic1. Distribution of the Sample Surveyed as to the Clinical Diagnosis Graphic (N=266)

Of the 156 patients with a clinical diagnosis of psychotic disorder, $\mathrm{n}=44$ (28\%) presented a comorbidity of drug or alcohol use or aroused suspicion of induced psychosis.

Table 2 displays the distribution of the first clinical diagnosis, divided into three main groups: psychotic disorders, mental retardation and other diagnoses (including organic disorders, personality disorders, and disorders resulting from psychoactive substances). As for the crime, there were broken up into three categories: crimes against life, such as homicide and bodily harm; sex crimes, such as rape and violent sexual assault; and others, such as assault, drug trafficking, dealing in stolen property, breaking and entering, etc. These data were analyzed according to the Chi-squared test and were considered significant $(\mathrm{p}<0.05)$. 
Eduardo H. Teixeira \& Paulo Dalgalarrondo

Table2. Primary Diagnosis and type of crime committed $(n=269)$

\begin{tabular}{|l|c|c|c|c|}
\hline \multicolumn{1}{|c|}{ Diagnosis } & Crime against Life & Sex Crime & Other Crimes & \multicolumn{1}{c|}{ Total } \\
\hline Psychosis & $97(62,2 \%)$ & $25(16,0 \%)$ & $34(21,8 \%)$ & $156(100 \%)$ \\
\hline Mental Retardation & $(68,3 \%)$ & $(51,0 \%)$ & $(43,6 \%)$ & \\
\hline & $17(30,9 \%)$ & $14(25,5 \%)$ & $24(43,6 \%)$ & $55(100 \%)$ \\
\hline Other Diagnoses & $(12,0 \%)$ & $(28,6 \%)$ & $(30,8 \%)$ & \\
\hline & $28(48,3 \%)$ & $10(17,2 \%)$ & $20(34,5 \%)$ & $58(100 \%)$ \\
\hline Total & $(19,7 \%)$ & $(20,4 \%)$ & $(25,6 \%)$ & \\
\hline
\end{tabular}

Chi-squared Test $x^{2}=17,3(d f=4) ; p<0,002$

Regarding the type of crime, a predominance of crimes against life was found ( $\mathrm{n}=142,52.8 \%$ ), with the group of psychotic patients having the greatest frequency of association with this type of crime $(\mathrm{n}=97,68.3 \%)$. Of these 97 crimes committed by psychotic, 87 (89.7\%) resulted in death, of which 30 (34.5\%) were committed against close relatives: eight killed their mothers, seven killed their wives, six killed their fathers, six killed a brother, and three killed another relative, such as a cousin or fatherin-law.

Of the group of subjects with mental retardation $(\mathrm{n}=55)$, there was a preponderance of the so-called "other crimes" $n=24(43.6 \%)$, that is, types of offenses that did not include crimes against life or sex crimes. In this group, crimes were quite heterogeneous and generally characterized by a lack of complexity and premeditation, such as petty theft, breaking and entering, drug possession, etc. If these kinds of crimes had been subdivided into sub-types, crimes against life would become the most frequent among those committed by subjects with mental retardation.

There was an interesting finding in this diagnostic group, regarding the 14 sex crimes. In 11 of the cases $(78.5 \%)$, the crime was committed against victims under 14 years of age.

An analysis was also made considering only the two main observed diagnostic groups (psychoses and mental retardation) and the respective crimes committed, classified solely within the groups of crimes against life or sex crimes. The data were analyzed in a $2 \times 2$ table using the Chi-squared test, displayed in table 3.

Table3. Crimes committed by individuals with psychosis and mental retardation $(n=153)$

\begin{tabular}{|l|c|c|c|}
\hline \multicolumn{1}{|c|}{ Diagnosis } & Crime against Life & Sex Crime & Total \\
\hline Psychosis & $97(79,5 \%)$ & $25(20,5 \%)$ & $122(100 \%)$ \\
\hline Mental Retardation & $(85,1 \%)$ & $(64,1 \%)$ & \\
\hline & $17(54,8 \%)$ & $14(45,2 \%)$ & $31(100 \%)$ \\
\hline Total & $(14,9 \%)$ & $(35,9 \%)$ & \\
\hline
\end{tabular}

Chi-squared Test $x^{2}=7,9(d f=1) ; p<0,005$

Psychotic patients still remain the group that committed the most crimes against life when compared to those with mental retardation. Among subjects with mental retardation, although the most frequent type of crime was against life, this group committed proportionally and in a statistically significant manner more sex crimes when compared to psychotics.

\section{DisCUSSION}

The studied sample of male patients makes up $66 \%$ of total patients committed at the institution at the beginning of the study, considering only the male patient population at the institution. Those cases that were not studied among the male patient population were those patients that had been recently committed $(\mathrm{n}=126 ; 30 \%)$, those that still had not been examined by an expert and therefore lacked a report in their chart, and those patients that were defendants $(n=12 ; 3 \%)$ who were still awaiting sentencing and were committed for treatment of an acute episode.

Considering the socio-demographic aspects of the studied population, the results are in accordance with the literature, both with regards to the proportion of the male population and to age range. The apparent low level of education and the preponderance of unmarried inmates are also compatible with findings in the literature.

As to the clinical diagnosis, patients with psychotic disorders are in the majority, $(n=156 ; 58 \%)$, which is also in accordance with the findings in the international literature ${ }^{14-16}$. This study found a 
small proportion of diagnoses of personality disorders $(n=8,3 \%)$, similar to what was observed in the study carried out at the House of Custody and Psychiatric Treatment of Rio Grande do Sul ${ }^{12}$, although far below what was observed in the English study ${ }^{14}$, which found a percentage around $41 \%$. This discrepancy is accounted for by the fact that the latter study counted every diagnosis of personality disorder, even when it appeared as comorbidity. In fact, there are problems with evaluating clinical diagnosis in this kind of sample, because one third or more of these cases present with two or more clinical diagnoses.

Among the psychotic inmates $(n=156)$, there is a preponderance of crimes against life $(n=97 ; 62.2 \%)$. This was somewhat to be expected, as only the more severe crimes result in an incarceration sentence according to the Penal Code. Therefore, the non-culpable criminals that committed this kind of crime have to, by law, remain in state custody, committed to a facility. This finding is also in accordance with the international scientific literature, which found a predominance of homicides and other violent crimes committed by individuals diagnosed with psychosis ${ }^{14}$.

Of those crimes that resulted in the death of the victim ( $\mathrm{n}=87 ; 90 \%)$, in $30(35 \%)$ of the cases, the victim was a close relative ${ }^{7}$. This is a significant factor, as research that considers the victim and his or her relation to the aggressor in this particular population is still quite scarce. On comparing homicidal aggression of psychotic patients to that of non-psychotic patients, in accordance with a study conducted by Hafner and Boker $(1982)^{20}$, which assessed the records of all attempted murders by mentally ill individuals in Germany over ten years, one finds an elevated rate of victims that are related to psychotics ${ }^{21}$.

Why do psychotic subject commit crimes against close relatives? It is possible that some of these crimes were committed during a period of delirious activity and that the relatives were part of the delusion. Furthermore, the greater proximity and intimacy with relatives, imposed by the very psychosocial condition that the psychosis entails (dependence on relatives and loss of autonomy) could make it more likely that close relatives are "chosen" as victims.

With regards to the subjects with mental retardation, when compared to psychotic subjects, although the most frequent type of crime was crime against life, this group was revealed to have had a proportionally higher frequency of sex crimes (45\% of subjects with mental retardation and $20 \%$ of subjects with psychoses). In this same group, it is worth noting a common characteristic of most victims, who in 11 cases were under age 14 and in one case was a 76 year old woman.

In the 1960s, Walker (1965) compared 305 men with light to severe mental retardation committed to forensic hospitals with the same number of men over 17 who had been tried for crimes in English courts. He determined that the mentally handicapped men had committed six times more sex offenses than the control group without mental retardation ${ }^{22}$. Later, Walter and MacCabe (1973) found in another sample of 942 men who had committed assaults that the subjects with mental retardation, though making up only one third of the sample, were responsible for nearly $60 \%$ of all sexual assaults. Walter and MacCabe alse determined that these assaults were committed mainly against children ${ }^{23}$. More recently, Noreik et al (1993) assessed 65 sex crimes committed by subjects with mental retardation and determined that two thirds of the victims had been under 16 years of age $e^{24}$.

This latter finding regarding the age of the victim, significant also in this study, indicates that characteristics of the victim may play an important role in sex crimes committed by subjects with mental retardation. The low age range suggests that these victims might offer less resistance to the aggressor. Furthermore, one may speculate about a process through which subjects with mental retardation, perhaps through identification, might be able to become close with children, allowing an intimacy from which the individual would move on to sexual and aggressive acts. Difficulties in making socially acceptable sexual approaches may also act as a factor in sex crimes committed by individuals with mental retardation.

In sum, there are indications in the international literature that associate sex crimes to individuals with mental retardation and whose victims tend to be children. The data in this study reinforce this possibility.

\section{Conclusions}

This study finds that the examined population at the House of Custody and Psychiatric Treatment is similar to that of other institutions in other countries with the same profile: young-adult patients who 
are predominantly male and who have diagnoses of psychosis, mental retardation and a third group with personality disorders and abuse/dependence on psychoactive substances.

The findings in terms of the characteristics of the victims, in the cases of homicides committed by psychotics just as in sex crimes committed by individuals with mental retardation, indicate that some aspects of the victim play a significant role in crime and should be the focus of further and deeper study.

Finally, studies of violence as it relates to specific psychiatric populations could add information to the process of risk identification and prevention of violence committed by individuals with severe mental disorders.

\section{REFERENCES}

[1] Binder RL. Are the mentally ill dangerous? J Am Acad Psychiatry Law. 1999;27(2):189-201.

[2] Mullen PE. Forensic mental health. Br J Psychiatry. Apr 2000;176:307-311.

[3] Shaw J, Hunt IM, Flynn S, et al. Rates of mental disorder in people convicted of homicide. National clinical survey. Br J Psychiatry. Feb 2006;188:143-147.

[4] Vevera J, Hubbard A, Vesely A, Papezova H. Violent behaviour in schizophrenia. Retrospective study of four independent samples from Prague, 1949 to 2000. Br J Psychiatry. Nov 2005; 187:426-430.

[5] Wallace C, Mullen P, Burgess P, Palmer S, Ruschena D, Browne C. Serious criminal offending and mental disorder. Case linkage study. Br J Psychiatry. Jun 1998;172:477-484.

[6] Arboleda-Florez J. Contemporary Forensic Psychiatry: a Review. Vol II. Athens: Beta Medical Publishers; 2005.

[7] McGrath M, Oyebode F. Characteristics of perpetrators of homicide in independent inquiries. Med Sci Law. Jul 2005;45(3):233-243.

[8] Taylor PJ, Gunn J. Homicides by people with mental illness: myth and reality. Br J Psychiatry. Jan 1999;174:9-14.

[9] Monahan J. Mental disorder and violent behavior. Perceptions and evidence. Am Psychol. Apr 1992;47(4):511-521.

[10] Taborda JG. Forensic psychiatry today: a Latin American view. World Psychiatry. Jun 2006;5(2):96.

[11] Conill EM, Pieralisi CA, Peres MA, et al. [Public figures on trial: an assessment of the use of the "jury court" technique for city officials in Santa Catarina, Brazil]. Cad Saude Publica. Oct-Dec 1998;14(4):857-861.

[12] Taborda JG, Cardoso RG, Morana HC. Forensic psychiatry in Brazil. An overview. Int J Law Psychiatry. Sep-Dec 2000;23(5-6):579-588.

[13] Taborda JG. Criminal Justice System in Brazil: functions of a forensic psychiatrist. Int J Law Psychiatry. Jul-Oct 2001;24(4-5):371-386.

[14] Taylor PJ, Leese M, Williams D, Butwell M, Daly R, Larkin E. Mental disorder and violence. A special (high security) hospital study. Br J Psychiatry. Mar 1998;172:218-226.

[15] Coid J, Kahtan N, Gault S, Cook A, Jarman B. Medium secure forensic psychiatry services: comparison of seven English health regions. Br J Psychiatry. Jan 2001;178(1):55-61.

[16] Tuninger EE, Levander S, Bernce R, Johansson G. Criminality and aggression among psychotic in-patients: frequency and clinical correlates. Acta Psychiatr Scand. Apr 2001;103(4):294-300.

[17] Teixeira EHO, C; Moscatello, R; Dalgalarrondo, P. Risco de violência e precariedade de recursos assistenciais para casos agudos. Brazilian Journal of Psychiatry. 2005;54(2):155-156.

[18] Marzuk PM. Violence, crime, and mental illness. How strong a link? Archives of general psychiatry. Jun 1996;53(6):481-486.

[19] OMS. Classificação dos Transtornos Mentais e de Comportamento. 10a ed. Porto Alegre: Artes Médicas; 1993.

[20] Hafner HB, W. Crimes of violence by mentally abnormal offenders. Vol I: Cambridge University Press; 1984.

[21] Josef FS, JAD. Mental disease and violent behavior: new evidence from research Brazilian Journal of Psychiatry. 2003;52(2):127-135. 
Psychiatric Diagnosis, Type of Crime and Victim Profile: A Study of the Population of a High-Security Forensic Hospital in the State of Sao Paulo, Brazil

[22] Walker N. Crime and Punishment in Great Britain. Vol I. Edinburgh Edinburgh University Press; 1965.

[23] Walter NM, S. Crime and Insanity in England. Vol II. Edinburgh Edinburgh University Press; 1973.

[24] Noreik K, Grunfeld B. [Mental retardation and sexual abuse. 65 mentally retarded men submitted to forensic psychiatric examination because of sex offences]. Tidsskr Nor Laegeforen. Jun 20 1993;113(16):2003-2005.

\section{AUTHORS' BIOGRAPHY}

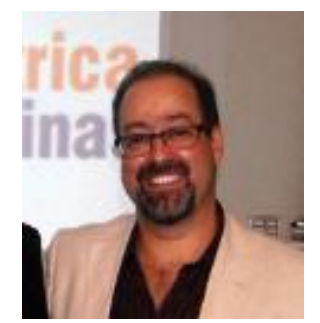

Dr. Eduardo H. Teixeira, is a Forensic Psychiatrist Master / Doctor in Mental Health by State University of Campinas (Unicamp), São Paulo, Brazil and Professor of Forensic Psychiatry and Clinical Psychiatry in Medical School at Pontifice Catholic University of Campinas (PUC), São Paulo, Brazil

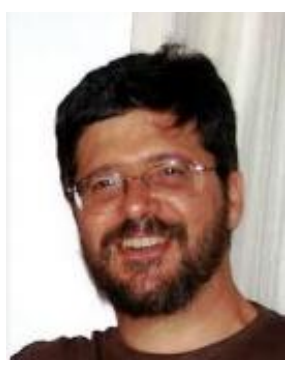

Dr. Paulo Dalgalarrondo, is a Clinical Psychiatrist and Head of Department in Medical School at State University of Campinas (Unicamp), São Paulo, Brazil and also Professor of Clinical Psychiatry in Medical School at State University of Campinas (Unicamp), São Paulo, Brazil 